\title{
NORMAS PARA MANUSCRITOS SUBMETIDOS ÀS REVISTAS BIOMÉDICAS: ESCRITA E EDIÇÃO DA PUBLICAÇÃO BIOMÉDICA (TRADUÇÃO INTEGRAL DO TEXTO)
}

\author{
UNIFORM REQUIREMENTS FOR MANUSCRIPTS SUBMITTED TO BIOMEDICAL \\ JOURNALS: WRITING AND EDITING FOR BIOMEDICAL PUBLICATION
}

\author{
Carlos Alberto Guimarães, TCBC-RJ'; \\ Grupo de Revisão Sistemática do Rio de Janeiro ${ }^{2}$
}

(Atualização em outubro de 2008)

Ética na Publicação: Patrocínio,Autoria e Responsabilidade

Comitê Internacional dos Editores de Revistas Médicas

I. Declaração dos Objetivos

A. Sobre as Normas

B. Potenciais Usuários das Normas

C. Como Usar as Normas

\section{Considerações Éticas na Condução e na Comunicação da} Pesquisa

A. Autoria e Contribuição

1. Autores

2. Colaboradores Mencionados nos Agradecimentos

B. Editoria

1. O Papel do Editor

2. Liberdade Editorial

C. Revisão pelos Pares

D. Conflitos de Interesse

1. Potenciais Conflitos de Interesse Relacionados aos Compromissos de Cada Autor

2. Potenciais Conflitos de Interesse Relacionados ao Financiamento do Projeto

3. Potenciais Conflitos de Interesse Relacionados aos Compromissos dos Editores, do Corpo Editorial da Revista ou dos Revisores

E. Privacidade e Confidencialidade

1. Pacientes e Sujeitos de Pesquisa

2. Autores e Revisores

F. Proteção dos Seres Humanos e Animais em Pesquisa

III. Questões Editorias e de Publicação Relacionadas às Revistas Biomédicas

A. Obrigação de Publicar Estudos Negativos

B. Correções, Retratações e "Alerta sobre Questões Éticas"
C. Direitos Autorais

D. Publicações Repetidas

1. Duplicação de submissão

2. Publicação Redundante

3. Publicação Secundária Aceitável

4. Manuscritos Concorrentes Baseados no Mesmo Estudo

a. Diferenças na Análise ou na Interpretação

b. Diferenças nos Métodos ou nos Resultados Relatados

5. Manuscritos Concorrentes Baseados no Mesmo Banco de

Dados

E. Correspondência

F. Suplementos, Fascículos Temáticos e Séries Especiais

G. Publicação Eletrônica

H. Propaganda

I. Revistas Médicas e os Meios de Comunicação

J. Obrigação de Registrar os Ensaios Clínicos

\section{Preparação e Submissão do Manuscrito}

A. Preparando um Manuscrito para Submissão às Revistas Biomédicas

1. a. Princípios Gerais

b. Diretrizes para Relatos dos Estudos com Desenhos Específicos

2. Página de Rosto

3. Página da Declaração de Conflito de Interesse

4. Resumo e Palavras-Chave

5. Introdução

6. Métodos

a. Seleção e Descrição dos Participantes

b. Informações Técnicas

c. Estatística

7. Resultados

8. Discussão

9. Referências

a. Considerações Gerais Relacionadas às Referências

b. Estilo e Formato das Referências

1. Professor Titular do Curso de Graduação de Medicina do Centro Universitário Serra dos Órgãos (Teresópolis, RJ); Professor Adjunto do Departamento de Cirurgia da Faculdade de Medicina da Universidade Federal do Rio de Janeiro; Membro do Grupo de Pesquisa Núcleo de Comunicação Científica em Cirurgia do CNPq; Membro do Conselho de Revisores da Revista do Colégio Brasileiro de Cirurgiões.

Recebido em 12/10/2008

Aceito para publicação em 25/10/2008

Conflito de interesses: nenhum

Fonte de financiamento: nenhuma

Normas para Manuscritos Submetidos às Revistas Biomédicas: Escrita e Edição da Publicação Biomédica (Tradução Integral do Texto) 
10. Tabelas

11. Ilustrações (Figuras)

12. Legendas das Ilustrações (Figuras)

13. Unidades de Medida

14. Abreviações e Símbolos

B. Envio do Manuscrito à Revista

\section{Referências}

A. Referências Citadas neste Documento

B. Outras Fontes de Informação Relacionadas às Revistas
Biomédicas

VI. Sobre o Comitê Internacional dos Editores de Revistas
Médicas

VII. Autores das Normas

VIII. Uso, Distribuição e Tradução das Normas

IX. Perguntas

\section{DECLARAÇÃO DOS OBJETIVOS}

\section{A. Sobre as Normas}

Um pequeno grupo de editores de revistas de Medicina Interna se encontrou informalmente em Vancouver, Columbia Britânica, em 1978, a fim de estabelecer as diretrizes para o formato dos manuscritos submetidos as suas revistas. Esse grupo ficou conhecido como o Grupo de Vancouver. Suas normas para os manuscritos, contendo os formatos das referências bibliográficas elaborados pela National Library of Medicine (NLM), foram publicadas, pela primeira vez, em 1979. O Grupo de Vancouver se expandiu e se tornou o Comitê Internacional dos Editores de Revistas Médicas (CIERM), que se reúne anualmente. O CIERM ampliou gradualmente seu campo de ação, a fim de incluir princípios éticos relacionados à publicação nas revistas biomédicas.

O CIERM produziu várias edições das "Normas para Manuscritos Submetidos às Revistas Biomédicas". Com o passar dos anos, surgiram questões que iam além da preparação do manuscrito, as quais resultaram na elaboração de várias declarações, publicadas em separado, sobre política editorial. As Normas foram revisadas na íntegra em 1997; as seções foram atualizadas em maio de 1999 e em maio de 2000. Em maio de 2001, o CIERM revisou as seções relacionadas com potencial conflito de interesse. Em 2003, o Comitê revisou e reorganizou todo o documento e incorporou ao texto as Declarações Independentes. O Comitê preparou a presente revisão em 2008.

O conteúdo completo das "Normas para Manuscritos Submetidos às Revistas Biomédicas" pode ser reproduzido com finalidades educacionais, sem fins lucrativos e sem ônus dos direitos autorais; o comitê encoraja a distribuição desse material.

Solicita-se às revistas, que concordam em utilizar as Normas, mencionar, nas instruções aos autores, que as suas normas de publicação estão de acordo com as Normas, citando a presente versão. As revistas que desejam ser listadas no endereço www.icmje.org como uma publicação que segue as Normas, devem entrar em contato com a secretaria do CIERM.

O CIERM é um pequeno grupo de trabalho das revistas de Medicina Interna e não uma organização aberta a filiações. Ocasionalmente, o CIERM convidará um novo membro, quando o comitê considerar que uma nova revista ou organização poderá oferecer uma nova perspectiva. Existem organizações abertas a filiações dos editores e de outros profissionais envolvidos com publicações biomédicas, tais como a World Association of Medical Editors www.WAME.org e o Council of Science Editors www.councilofscienceeditors.

\section{B. Potenciais Usuários das Normas}

O CIERM criou primordialmente as Normas, para ajudar os autores e os editores na tarefa mútua de criar e distribuir relatos precisos, claros e facilmente acessíveis dos estudos biomédicos. As seções iniciais tratam dos princípios éticos ligados ao processo da avaliação, do aperfeiçoamento e da publicação dos manuscritos nas revistas biomédicas e das relações entre os editores, os autores, os revisores e os meios de comunicação. As últimas seções abordam os aspectos mais técnicos da preparação e da submissão dos manuscritos. $\mathrm{O}$ CIERM acredita que todo o documento seja pertinente tanto para os autores como para os editores.

As Normas podem fornecer informações úteis sobre o processo de escrita e edição das revistas biomédicas a muitas outros interessados (revisores, editores, meios de comunicação, pacientes e seus familiares e leitores de um modo geral).

\section{C. Como Usar as Normas}

As Normas estabelecem os princípios éticos na condução e na comunicação da pesquisa e fornecem as recomendações com relação aos elementos específicos da edição e da escrita. Essas recomendações estão, em grande parte, embasadas na experiência compartilhada por um número razoável de editores e de autores, coletada ao longo de muitos anos e não em resultados de uma investigação metódica e planejada, que tem por objetivo ser "baseada em evidências". Quando possível, as recomendações são acompanhadas de uma fundamentação que as justifica; dessa forma, o documento tem um objetivo educativo.

Será útil para os autores seguirem as recomendações deste documento, sempre que possível, porque isso, como está descrito nas explicações, melhora a qualidade e a clareza dos manuscritos submetidos a qualquer revista, além de facilitar a edição. Ao mesmo tempo, cada revista tem normas editoriais, adequadas especificamente aos seus objetivos. Assim, os autores devem seguir as instruções aos autores específicas da revista que eles escolheram para submeter seus 
manuscritos, observando os temas adequados para aquela revista e os tipos de artigos que podem ser submetidos (por exemplo, artigos originais, revisões ou relatos de caso).

\section{CONSIDERAÇÕES ÉTICAS NA CONDUÇÃO E NA COMUNICAÇÃO DA PESQUISA}

\section{II.A. Autoria e a Contribuição}

\section{A. 1. Autores}

Considera-se geralmente um "autor" alguém que fez contribuições intelectuais relevantes para um estudo publicado, já que a autoria biomédica tem importantes implicações acadêmicas, sociais e financeiras (1). Antigamente, os leitores raramente recebiam as informações sobre as contribuições, para os estudos, das pessoas mencionadas na lista dos autores ou nos Agradecimentos (2). Atualmente, algumas revistas solicitam e publicam as informações sobre as contribuições de cada pessoa, mencionada como participante, em um estudo submetido, pelo menos com relação às pesquisas originais. Solicita-se aos editores que desenvolvam e implementem uma política de contribuição, além de uma política de identificação de quem é responsável pela integridade do trabalho como um todo.

Embora as políticas de contribuição e de garantia removam muito da ambigüidade em torno das colaborações, elas não resolvem a questão da quantidade e da qualidade da contribuição necessária para a qualificação da autoria. $\mathrm{O}$ CIERM recomendou os seguintes critérios para autoria; esses critérios também são apropriados para aquelas revistas que distinguem os autores daqueles que fizeram outras contribuições:

- O crédito para autoria deve basear-se em: 1) contribuições substanciais à concepção e ao desenho, à coleta de dados ou à análise e à interpretação dos dados; 2) redação ou revisão crítica do artigo, a fím de garantir um conteúdo intelectual importante e 3) aprovação final da versão a ser publicada. Os autores devem satisfazer às condições 1,2 e 3 .

- Quando um grande grupo multicêntrico realizou o trabalho, o grupo deve identificar os membros que aceitam a responsabilidade direta pelo manuscrito (3). Esses membros devem preencher todos os critérios de autoria/contribuição definidos acima e os editores deverão solicitar a eles que preencham as declarações específicas da revista com relação à autoria e ao conflito de interesse. Quando se submete um manuscrito cuja autoria seja um grupo, um autor responsável pela correspondência deve indicar claramente a forma preferida de citação e identificar todos os autores, assim como o nome do grupo. As revistas costumam mencionar os outros membros do grupo nos Agradecimentos. A NLM indexa o nome do grupo e os nomes dos autores que o grupo identificou como diretamente responsáveis pelo manuscrito; ela também lista os nomes dos colaboradores que estão mencionados nos Agradecimentos.

- A obtenção de financiamento, a coleta de dados ou a supervisão do grupo de pesquisa, não justificam, por si só, a autoria.
- Todas as pessoas mencionadas como autores devem estar qualificadas para a autoria e todas aquelas qualificadas devem ser mencionadas.

- Cada autor deve ter participado efetivamente do trabalho, para poder assumir a responsabilidade pública por partes definidas do conteúdo.

Atualmente, algumas revistas também solicitam que um ou mais autores, denominados de "avalistas", sejam identificados como aqueles que têm a responsabilidade pela integridade do trabalho como um todo, desde a sua concepção até o artigo publicado. Essa informação deve ser publicada.

Cada vez mais, a autoria dos ensaios multicêntricos é atribuída a um grupo. Todos os membros do grupo listados como autores devem preencher todos os critérios acima para a autoria/contribuição.

Os membros do grupo devem decidir, em conjunto, quem serão os colaboradores/autores antes da submissão do manuscrito para publicação. $\mathrm{O}$ autor/avalista responsável pela correspondência deve estar apto a explicar a escolha dos autores e a ordem em que os nomes deles aparecem na lista. Não é função dos editores tomar decisões concernentes à autoria/ colaboração ou arbitrar conflitos relacionados à autoria.

II.A. 2. Colaboradores Mencionados nos Agradecimentos

Todas as pessoas que contribuíram, mas que não preenchem os critérios de autoria, devem ser mencionadas em uma seção de Agradecimentos. Exemplos daqueles que merecem um agradecimento: alguém que prestou uma ajuda puramente técnica, um auxílio na redação ou um chefe de departamento que tenha dado um apoio geral. Os editores devem pedir aos autores responsáveis pela correspondência que declarem se tiveram auxílio no delineamento do estudo, na coleta ou análise dos dados ou na preparação do manuscrito. Nesse caso, os autores devem mencionar quem foram essas pessoas que prestaram esse auxílio e, se for o caso, identificar a origem do pagamento por essa ajuda no artigo publicado. Os apoios financeiros e material devem também ser agradecidos. Aqueles que contribuíram materialmente para o artigo, mas cujas contribuições não justificam a autoria, podem ser mencionados sob um título de "investigadores clínicos" ou "investigadores participantes" e suas funções ou contribuições devem ser descritas assim: "prestaram orientação científica", "revisaram criticamente o projeto do estudo", "coletaram os dados" ou "prestaram assistência aos sujeitos de pesquisa". Como os leitores podem inferir que aqueles mencionados nos Agradecimentos endossam os dados e as conclusões, todas as pessoas precisam dar uma permissão por escrito para serem incluídas nessa seção.

\section{B. Editoria}

\section{II.B.1. O papel do Editor}

O editor de uma revista é a pessoa responsável por todo o seu conteúdo. Os proprietários e os editores das revistas médicas se esforçam com um objetivo comum - a publicação de um periódico confiável e de fácil leitura, produzido tendo em mente os custos e os objetivos da publicação. Con- 
tudo, as funções dos proprietários e dos editores são diferentes. Os proprietários têm o direito de indicar e dispensar os editores e tomar as importantes decisões administrativas, nas quais os editores devem ter a máxima participação possível. Os editores devem ter total autoridade na determinação do conteúdo editorial da revista. O conceito de liberdade editorial deve ser defendido com determinação pelos editores, mesmo que coloquem seus cargos em risco. Para garantir, na prática, tal liberdade, o editor deve ter acesso direto aos proprietários do mais alto escalão e não somente a um gerente que represente esses proprietários.

Os editores das revistas médicas devem ter um contrato que especifique claramente seus direitos e deveres, bem como os termos gerais da contratação e a definição dos mecanismos para a resolução dos conflitos.

Um conselho editorial independente pode ser útil para ajudar o editor a estabelecer e manter uma política editorial.

\section{II.B.2. Liberdade editorial}

O CIERM adota a definição de liberdade editorial da World Association of Medical Editors http://www.wame.org/ wamestmt.htm. Essa definição estabelece que a liberdade ou independência editorial é o conceito em que os editores-chefe devem ter total autoridade sobre o conteúdo editorial das suas revistas, assim como sobre o melhor momento para publicar aquele conteúdo. Os proprietários da revista não devem interferir na avaliação, na seleção ou na edição dos artigos, seja diretamente ou pela criação de um ambiente que influencie fortemente as decisões. Os editores devem basear suas decisões na validade do trabalho e na sua importância para os leitores e não no sucesso comercial da revista. Os editores devem ser livres para expressar pontos de vista críticos e responsáveis sobre todos os aspectos da Medicina, sem medo de represálias, mesmo que tais opiniões entrem em conflito com os objetivos comerciais da editora. Os editores e as associações dos editores têm a obrigação de apoiar o conceito da liberdade editorial e de levar as transgressões importantes a essa liberdade ao conhecimento das comunidades internacionais médicas, acadêmicas e leigas.

\section{II.C. Revisão pelo Pares}

A avaliação crítica não enviesada e independente é uma parte intrínseca de todo trabalho acadêmico, incluindo o processo científico. A revisão pelos pares é a avaliação crítica dos manuscritos submetidos às revistas por especialistas que não fazem parte do corpo editorial. A revisão pelos pares pode ser vista como uma extensão importante do processo científico. Embora seu real valor tenha sido pouco estudado e esteja sendo amplamente debatido (4), a revisão pelos pares auxilia os editores a decidir que artigos são adequados para as suas revistas e ajuda os autores e os editores nos seus esforços para melhorar a qualidade dos relatos. Uma revista com o sistema de revisão pelos pares submete a uma avaliação externa a maioria dos seus artigos de pesquisa publicados. O número e o tipo dos manuscritos enviados para a revisão, o número de revisores, os procedimentos da revisão e a aceitação das opiniões dos revisores podem variar. No interesse da transparência, cada revista deve divulgar suas políticas nas Instruções aos Autores.

\section{II.D. Conflitos de Interesse}

A confiança do público no processo de revisão pelos pares e a credibilidade dos artigos publicados dependem, em parte, da maneira como se lida com o conflito de interesse durante a escrita, a revisão pelos pares e a tomada da decisão editorial. O conflito de interesse existe quando um autor (ou a instituição do autor), um revisor ou um editor tem relações financeiras ou pessoais que influenciam impropriamente (viés) as suas ações (essas relações também são chamadas de compromissos duplos, interesses conflitantes ou lealdades conflitantes). Essas relações variam desde aquelas com potencial desprezível de influência, até aquelas com grande potencial de influenciar os julgamentos. Nem todas as relações caracterizem um verdadeiro conflito de interesse. Por outro lado, o potencial para o conflito de interesse pode existir independentemente de o indivíduo acreditar ou não que a relação afete o seu julgamento científico. As relações financeiras (emprego, consultorias, propriedade acionária, honorários e parecer remunerado de especialista) são os conflitos de interesse mais facilmente identificáveis e com maiores probabilidades de abalar a credibilidade da revista, dos autores e da própria ciência. No entanto, os conflitos podem ocorrer por outras razões, tais como relações pessoais, competição acadêmica e paixão intelectual.

Todos os participantes no processo da revisão pelos pares e da publicação precisam declarar todas as relações que possam ser consideradas como um potencial conflito de interesse. A divulgação dessas relações é também importante em relação aos editoriais e aos artigos de revisão, pois pode ser mais difícil detectar vieses nesses tipos de publicações, do que em relatos de pesquisa original. Os editores podem utilizar a informação divulgada na declaração de conflitos de interesse e de fontes de financiamento como base para as decisões editoriais. Os editores devem publicar essas informações se acreditam que sejam importantes para o julgamento do manuscrito.

\section{II.C. Potenciais Conflitos de Interesse Relaciona- dos a Compromissos de Cada Autor}

Quando os autores submetem um manuscrito, seja um artigo ou uma carta, eles são responsáveis por declarar todas as relações financeiras e pessoais que possam influenciar o seu trabalho. Para evitar a ambigüidade, os autores precisam declarar explicitamente se existem ou não conflitos em potencial. Os autores devem fazer isso no manuscrito, em uma página de declaração de conflito de interesse, logo após a página de rosto, fornecendo, se necessário, pormenores adicionais em uma carta de submissão que acompanha o manuscrito (Ver Seção IV.A.3 Página de Declaração de Conflito de Interesse)

Os autores devem identificar aqueles que ajudaram na redação ou em outra parte do manuscrito e declarar a fonte de financiamento dessa ajuda. Os investigadores precisam declarar potenciais conflitos aos sujeitos de pesquisa e mencionar no manuscrito se o fizeram. Os editores precisam também decidir se publicam as informações reveladas pelos autores sobre potenciais conflitos. Na dúvida, é melhor errar, publicando as informações. 


\section{II.D.2. Potenciais Conflitos de Interesse Relaciona- dos ao Financiamento do Projeto}

Cada vez mais, os estudos individuais recebem financiamento das empresas comerciais, das fundações particulares e do governo. As condições desse financiamento têm o potencial de influenciar ou mesmo desacreditar a pesquisa.

Os cientistas têm uma obrigação ética de submeter para publicação os resultados confiáveis das suas pesquisas. Além disso, como responsáveis diretos pelo seu trabalho, os pesquisadores não devem fazer acordos que interfiram em seus acessos aos dados ou nas suas capacidades de analisar os dados com independência e de preparar e publicar os manuscritos. Os autores devem descrever o papel do patrocinador do estudo, se for o caso, no delineamento do estudo; na coleta, na análise e na interpretação dos dados; na redação do texto e na decisão de submeter o manuscrito para publicação. Se a fonte de financiamento não teve nenhuma participação nesse sentido, isso deve ser mencionado pelos autores. Os vieses potencialmente introduzidos, quando os patrocinadores estão diretamente envolvidos na pesquisa, são análogos aos vieses metodológicos de outras naturezas. Algumas revistas, portanto, optam por incluir a informação sobre a participação dos patrocinadores na seção de Métodos.

Os editores podem solicitar que os autores de um estudo, patrocinado por uma agência com interesse financeiro ou de propriedade nos desfechos, assinem uma declaração nos seguintes termos: "Eu tive acesso a todos os dados deste estudo e assumo a total responsabilidade pela integridade desses dados e pela precisão da análise dos mesmos". Os editores devem ser encorajados a revisar as cópias do protocolo e/ou dos contratos relacionados com estudos de projetos específicos, antes da aceitação desses estudos para publicação. Os editores podem decidir não aceitar um artigo se um patrocinador reivindicou controle sobre o direito de publicação dos autores.

\section{II.D.3. Potenciais Conflitos de Interesse Relaciona- dos aos Compromissos dos Editores, do Corpo Editorial ou dos Revisores}

Os editores devem evitar selecionar revisores externos com conflitos de interesse potenciais evidentes; por exemplo, aqueles que trabalham no mesmo departamento ou instituição de qualquer um dos autores. Os autores fornecem freqüentemente aos editores os nomes daquelas pessoas que eles supõem que não devam ser convidadas para rever um manuscrito em virtude de potenciais conflitos de interesse, em geral de ordem profissional. Quando possível, os autores devem explicar ou justificar suas preocupações; essa informação é importante para os editores decidirem atender ou não a essas solicitações.

Os revisores precisam declarar para os editores quaisquer conflitos de interesse que possam influenciar suas opiniões sobre o manuscrito e devem recusar-se a revisar manuscritos específicos se eles se acharem com o julgamento comprometido. Assim como no caso dos autores, a não declaração dos potenciais conflitos, por partes dos revisores, significa que esses conflitos não existem ou existem e não foram declarados. Assim, os revisores devem ser solicitados a de- clarar explicitamente se os conflitos existem ou não. Os revisores não devem usar o conhecimento do trabalho, antes da sua publicação, em prol dos seus próprios interesses.

Os editores, que tomam as decisões finais sobre os manuscritos, não podem ter nenhum envolvimento pessoal, profissional ou financeiro com qualquer das questões que possam julgar. Os outros membros do corpo editorial, se participarem das decisões editoriais, devem fornecer aos editores uma descrição atualizada dos seus interesses financeiros (se tiverem relação com os julgamentos editoriais) e se absterem de qualquer decisão em que exista um conflito de interesse. $\mathrm{O}$ corpo editorial não deve utilizar, para ganho pessoal, as informações obtidas por meio do acesso aos manuscritos. Os editores devem publicar regularmente as declarações sobre potenciais conflitos de interesses relacionados com compromissos do corpo editorial.

\section{II.E. Privacidade e Confidencialidade}

\section{II.E.1. Pacientes e Sujeitos de Pesquisa}

Os pacientes têm o direito à privacidade, a qual não deve ser violada sem um consentimento informado. As informações sobre a identificação do paciente, incluindo os nomes, as iniciais e os números dos prontuários não devem ser publicadas em descrições por escrito, fotografias ou heredogramas, a menos que as informações sejam essenciais para os objetivos científicos e o paciente (ou seus pais ou responsáveis) dê seu consentimento informado por escrito para a publicação. O consentimento informado para essa finalidade requer que o paciente, que está sendo identificado, leia o manuscrito que vai ser publicado. Os autores devem mencionar a esses pacientes se, após a publicação, qualquer material que facilite a identificação estiver disponível via Internet do mesmo modo que na forma impressa. O consentimento do paciente, por escrito, deve ser arquivado com a revista e com os autores, de acordo com as leis e regulações locais. As leis pertinentes variam de local para local e as revistas devem estabelecer suas próprias políticas sob orientação legal.

Os detalhes de identificação devem ser omitidos quando não são essenciais. $O$ consentimento informado deve ser obtido, se houver qualquer dúvida de que o anonimato possa ser mantido. Por exemplo, cobrir a região dos olhos nas fotografias dos pacientes não é uma forma adequada de proteger o anominato. Se os dados identificadores são alterados para proteger o anonimato, como por exemplo nos heredogramas, os autores devem dar garantia de que as modificações não distorcem o significado científico e os editores devem registrar isso.

As normas para o consentimento informado devem ser incluídas nas Instruções aos Autores da revista. Quando o consentimento informado foi obtido, isso deve ser mencionado no artigo publicado.

\section{II.E.2. Autores e Revisores}

Os originais devem ser revistos, respeitando-se a confidencialidade dos autores. Ao submeter seus manuscritos para a revisão, os autores confiam aos editores os resultados do seu trabalho científico e do seu esforço criativo, dos 
quais suas reputações e carreiras podem depender. Os direitos dos autores podem ser violados pela revelação dos detalhes confidenciais da revisão dos seus manuscritos. Os revisores têm também direito à confidencialidade, que deve ser respeitada pelo editor. A confidencialidade pode ser quebrada se houver alegação de desonestidade ou fraude, mas, em caso contrário, deve ser respeitada.

Os editores não devem revelar informações sobre os manuscritos (incluindo o seu recebimento, o conteúdo, a situação no processo de revisão, as críticas dos revisores e a decisão final sobre a publicação) a ninguém, a não ser aos autores e aos revisores. Isso inclui as solicitações para utilização dos materiais para processos legais.

Os editores devem deixar claro para os seus revisores que os manuscritos enviados para revisão são comunicações sigilosas e são propriedade particular dos autores. Assim, os revisores e os membros do corpo editorial precisam respeitar os direitos dos autores, não discutindo publicamente o trabalho nem apropriando-se das suas idéias, antes que o manuscrito tenha sido publicado. Os revisores não devem ter permissão para fazer cópias dos manuscritos para seus arquivos e devem ser proibidos de compartilhá-los com outras pessoas, exceto com a permissão do editor. Os revisores devem devolver ou destruir as cópias dos manuscritos, após submeterem as revisões. Os editores não devem guardar cópias dos artigos rejeitados.

Os comentários do revisor não devem ser publicados ou de outra maneira tornados públicos, sem a permissão do revisor, do autor e do editor.

As opiniões divergem sobre se os revisores devem permanecer anônimos. Os autores devem consultar as Instruções aos Autores da revista que escolheram para submeter um manuscrito, para saber se as revisões são anônimas. Quando os comentários não são assinados, a identidade dos revisores não deve ser revelada ao autor ou a qualquer outra pessoa, sem a permissão do revisor.

Algumas revistas publicam os comentários dos revisores junto com o original. Esse procedimento não deve ser adotado sem o consentimento dos autores e dos revisores. Contudo, os comentários dos revisores devem ser enviados a outros revisores do mesmo manuscrito, o que ajuda os revisores a aprenderem sobre o processo de revisão. Os revisores podem ser notificados da decisão do editor de aceitar ou rejeitar um manuscrito.

\section{Pesquisa \\ II.F. Proteção dos Seres Humanos e Animais em}

Ao relatar experimentos com sujeitos de pesquisa, os autores devem mencionar se os procedimentos empregados estavam de acordo com os padrões éticos do comitê responsável por experimentação com seres humanos (institucional e nacional) e com a Declaração de Helsinki de 1975, revista em 2000 (5). Se houver dúvida sobre se a pesquisa foi conduzida de acordo com a Declaração de Helsinki, os autores precisam explicar a fundamentação do seu método e demonstrar que o comitê de ética institucional aprovou explicitamente os aspectos duvidosos do estudo. Ao relatar experimentos com animais, os autores devem mencionar se foram seguidas as diretrizes institucionais e nacionais para os cuidados e a utilização dos animais de laboratório.

\section{QUESTÕES EDITORIAIS E DE PUBLICAÇÃO RELACIONADAS À PUBLICAÇÃO NAS REVISTAS BIOMÉDICAS}

\section{III.A. Obrigação de Publicar Resultados Negativos}

Os editores devem considerar seriamente para publicação qualquer estudo bem feito sobre uma pergunta importante, relevante para seus leitores, se os resultados dos desfechos primários ou secundários sejam estatisticamente significativos. Deixar de submeter ou publicar estudos negativos é uma causa importante de viés de publicação.

\section{tões Éticas"}

III.B. Correções, Retratações e "Alerta sobre Ques-

Os editores devem inicialmente supor que os autores estão relatando um trabalho baseado em observações honestas. Não obstante, podem surgir dois tipos de problemas.

Primeiro, os erros podem ser percebidos em artigos já publicados, os quais exigem a publicação de uma correção ou errata sobre parte do trabalho. As correções devem aparecer em uma página numerada, incluída no índice, com a citação original completa e com um atalho para o artigo original e viceversa, em caso de publicação eletrônica. É concebível que um erro seja tão grave que possa viciar todo o trabalho, mas isso é pouco provável e deve ser tratado, caso a caso, pelos editores e pelos autores. Esses erros não devem ser confundidos com impropriedades trazidas à luz pelos novos conhecimentos científicos no curso normal de uma pesquisa. Isso não requer correções ou retratações.

O segundo tipo de problema é a fraude científica. Se surgirem grandes dúvidas sobre a honestidade ou a integridade do trabalho, quer submetido ou já publicado, é responsabilidade do editor assegurar que a questão seja devidamente esclarecida, geralmente pela instituição patrocinadora dos autores. Normalmente, não é responsabilidade dos editores conduzir uma completa investigação ou tomar uma decisão; essa responsabilidade é da instituição onde o trabalho foi feito ou da agência de fomento. $\mathrm{O}$ editor deve ser imediatamente informado da decisão final e, se um artigo com fraude foi publicado, a revista deve publicar uma retratação. Se esse método de investigação não resultar em uma conclusão satisfatória, o editor pode optar por conduzir sua própria investigação. Como alternativa à retratação, o editor pode decidir por publicar um alerta sobre questões éticas sobre os aspectos da condução ou da integridade do trabalho.

A retratação ou o alerta sobre questões éticas, assim designado, deve aparecer em uma página numerada numa seção de destaque da revista impressa, assim como na versão eletrônica, devendo constar no Índice e incluir em seu cabeçalho o título do artigo original. Ela não deve ser uma simples carta ao editor. Idealmente, o autor principal do artigo deve ser o mesmo da retratação, embora em certas circunstâncias, o editor possa aceitar retratações de outras pessoas responsáveis. O texto da retratação deve explicar o porquê da retratação e deve incluir a referência completa do artigo em questão.

Não se pode assumir a validade dos trabalhos anteriores do autor de um artigo fraudulento. Os editores podem solicitar à instituição do autor que ateste a validade dos arti- 
gos anteriores publicados nas suas revistas ou que esses trabalhos também sejam retratados. Se isso não for feito, os editores podem optar por publicar um anúncio, expressando a preocupação que a validade dos trabalhos publicados anteriormente pode ser questionada.

Pode ser útil para os editores que têm questões relacionadas com a má conduta editorial ou científica consultar os excelentes fluxogramas elaborados pelo Committee on Publication Ethics (COPE) www.publicationethics.org.uk. O COPE, criado em 1997, é um fórum no qual os editores das revistas com revisão pelos pares podem discutir as questões relacionadas com a integridade do registro científico; o comitê apóia e encoraja os editores a relatar, catalogar e instigar investigações dos problemas éticos no processo de publicação. O principal objetivo do COPE é funcionar como uma referência para os editores que se batem pela melhor maneira de lidar com possíveis violações da ética na pesquisa e na publicação.

\section{III.C. Direitos Autorais}

Muitas revistas biomédicas solicitam aos autores que transfiram os direitos autorais para a revista. Contudo, um número cada vez maior de revistas de "acesso livre" não faz essa solicitação. Os editores devem deixar claro, para os autores e para aqueles interessados em utilizar o conteúdo das revistas, sua posição sobre a transferência dos direitos autorais. A política dos direitos autorais sobre os artigos pode variar dentro de uma mesma revista: alguns conteúdos não podem ser submetidos à lei dos direitos autorais (por exemplo, artigos escritos por funcionários do governo norte-americano ou de outros países em função do seu trabalho); os editores podem dispensar, em alguns casos, a transferência dos direitos autorais; outros casos podem estar protegidos pelos direitos de publicação seriada (isto é, é permitido a publicação em outros meio que não revistas, incluindo as publicações eletrônicas).

\section{III.D.Publicações Repetidas}

\section{III.D.1. Duplicação de Submissão}

A maioria das revistas biomédicas não aceita os manuscritos que tenham sido simultaneamente submetidos a outras revistas. Entre as considerações principais que motivaram essa política estão: 1) a discordância em potencial quando duas (ou mais) revistas reivindicam o direito de publicar um manuscrito que tenha sido submetido simultaneamente a mais de uma revista e 2) a possibilidade de que duas ou mais revistas realizem, por desconhecimento e sem necessidade, o trabalho da revisão pelos pares, editem o mesmo manuscrito e publiquem o mesmo artigo.

Contudo, os editores de revistas diferentes podem decidir publicar simultanea ou conjuntamente um artigo, se eles acreditarem que, ao fazer isso, estarão agindo no melhor interesse da saúde pública.

\section{III.D.2. Publicação Redundante}

A publicação redundante (ou duplicada) é a publicação de um artigo que se sobreponha substancialmente com outro já publicado em versão impressa ou eletrônica.
Os leitores dos periódicos primários, sejam impressos ou sob forma eletrônica, merecem poder confiar que aquilo que estão lendo é original, a não ser que haja uma menção clara de que o artigo está sendo republicado por decisão do autor e do editor. As bases para essa posição são as leis internacionais dos direitos autorais, a conduta ética e a utilização eficiente dos recursos. A duplicação de publicação de uma pesquisa original é particularmente problemática, pois pode resultar em indevida contagem dupla ou ponderação inadequada dos resultados de um único estudo, o que distorcerá a evidência disponível.

A maioria das revistas não deseja receber artigos sobre um trabalho que já tenha sido relatado em grande parte em um artigo já publicado ou que esteja contido em outro artigo que tenha sido submetido ou aceito para publicação em outro lugar, em meio eletrônico ou impresso. Essa política não impede que a revista considere, para publicar, um artigo que tenha sido rejeitado por outra revista ou publique um texto completo que se segue à publicação de uma comunicação preliminar, por exemplo, um resumo ou um pôster apresentado em um congresso profissional. Essa mesma política também não impede que as revistas aceitem, para publicação, um artigo que tenha sido apresentado em um congresso científico, mas ainda não tenha sido publicado na íntegra ou que esteja sendo considerado para publicação sob forma de anais de congresso ou de outro formato similar. Reportagens na imprensa sobre futuros congressos não serão geralmente consideradas como quebra dessa regra, mas essas reportagens não podem conter dados adicionais ou cópias das tabelas e das ilustrações.

O CIERM não considera os resultados colocados nos registros de ensaios clínicos como publicação prévia, se os resultados são apresentados no mesmo registro, aceito pelo CIERM, no qual o registro inicial dos métodos do ensaio foi feito e se os resultados são apresentados sob a forma de um simples resumo ou tabela. O CIERM também acredita que o registro dos resultados deve ou citar a publicação completa dos resultados quando disponível ou incluir uma declaração que mencione que os resultados ainda não foram publicados em uma revista que tenha revisão pelos pares.

Quando submete um artigo, o autor deve sempre fazer uma declaração completa ao editor sobre todas as submissões e relatos anteriores (inclusive apresentações em congressos e colocação dos resultados nos registros) que possam ser vistos como publicação redundante ou duplicada. $\mathrm{O}$ autor precisa alertar o editor se o manuscrito inclui sujeitos de pesquisa sobre os quais os autores publicaram um artigo anterior ou sujeitos de pesquisa incluídos em artigo semelhante já enviado a outra publicação. Qualquer relato desse tipo deve ser mencionado e referenciado no novo artigo. As cópias desse material devem acompanhar o artigo submetido para ajudar o editor a decidir como lidar com o assunto.

Se uma publicação redundante ou duplicada está prestes a ocorrer ou está em fase de submissão, sem essa notificação, os autores devem esperar uma ação por parte do editor. No mínimo, se espera a rejeição imediata do manuscrito submetido. Se o artigo já foi publicado e o editor não estava ciente 
dessas violações, será provavelmente publicado um aviso sobre a publicação redundante ou duplicada com ou sem a explicação ou a aprovação do autor.

Relatos preliminares, para os meios públicos de comunicação, para as agências governamentais ou para as indústrias, das informações científicas contidas em um artigo ou carta ao editor, as quais foram aceitas, mas ainda não publicadas, viola a política editorial de muitas revistas. Esses relatos podem ser justificados quando o artigo ou a carta descreve grandes avanços terapêuticos ou riscos para a saúde pública, tais como efeitos adversos graves dos fármacos, das vacinas, dos produtos biológicos ou dos equipamentos médicos ou doenças de notificação compulsória. Esse tipo de comunicação não deve prejudicar a publicação, mas deve, com antecedência, ser discutida e aprovada pelo editor.

\section{III.D.3. Publicação Secundária Aceitável}

Certos tipos de artigos, tais como diretrizes elaboradas por agências governamentais ou organizações profissionais, podem precisar atingir o maior número possível de leitores. Nesses casos, os editores, às vezes, escolhem deliberadamente publicar matéria que está sendo publicado em outras revistas, com a concordância dos autores e dos editores daquelas revistas. A publicação secundária, por várias outras razões, no mesmo ou em outro idioma, principalmente em outros países, está justificada e pode ser útil, desde que sejam satisfeitas todas as condições mencionadas a seguir:

1. Os autores tenham obtido aprovação dos editores de ambas as revistas; o editor da publicação secundária precisa ter uma fotocópia, uma separata ou um manuscrito da versão primária.

2. A prioridade da publicação primária é respeitada por meio de um intervalo de publicação de no mínimo uma semana (exceto se negociado especificamente por ambos os editores).

3. O artigo da publicação secundária se destina para um grupo diferente de leitores; uma versão reduzida pode ser o suficiente.

4. A versão secundária reflete fielmente os dados e as interpretações da versão primária.

5. A nota de rodapé na página de rosto da versão secundária informa aos leitores, aos pares e às agências de documentação que o artigo foi publicado na íntegra ou em parte e menciona a referência primária. Essa nota deve ter o seguinte teor: "Este artigo está baseado em um estudo publicado inicialmente no [título da revista e referência completa]. A permissão para a publicação secundária deve ser gratuita.

6. O título da publicação secundária deve indicar que se trata de uma publicação secundária (republicação completa, republicação reduzida, tradução integral do texto ou tradução reduzida) de uma publicação primária. É importante ressaltar que a NLM não considera as traduções como "republicações" e não cita ou indexa as traduções quando o artigo original tiver sido publicado em uma revista indexada no MEDLINE.

7. Os editores das revistas que publicam simultaneamente em vários idiomas devem saber que a NLM indexa o idioma da versão primária. Quando o texto completo de um artigo aparece em mais de um idioma em um fascículo de uma revista (por exemplo, revistas canadenses com artigo em inglês e francês), ambos os idiomas são indicados na citação do MEDLINE (por exemplo, Mercer K. The relentless challenge in health care. Healthc Manage Forum. 2008 Summer;21(2):45. English, French. No abstract available. PMID:18795553.)

\section{III.D.4. Manuscritos Concorrentes Baseados no} Mesmo Estudo

A publicação dos manuscritos que tratam das controvérsias entre co-pesquisadores pode desperdiçar espaço na revista e confundir os leitores. Por outro lado, se os editores publicam conscientemente um original escrito por alguns membros de uma equipe de colaboradores, eles podem estar negando ao resto da equipe seus direitos legítimos de coautoria e aos leitores da revista, o acesso às legítimas diferenças de opinião sobre a interpretação de um estudo.

Existem dois tipos de submissões concorrentes: as submissões pelos colaboradores que discordam da análise e da interpretação do seu estudo e as submissões dos colaboradores que discordam sobre quais são os fatos e quais são os dados que serão relatados.

Deixando de lado a questão não resolvida da propriedade dos dados, as observações seguintes podem ajudar os editores e aqueles que tratam desses problemas.

\section{D.4.a. Diferenças na Análise ou na Interpretação}

Se a controvérsia está centrada na análise ou na interpretação dos dados, os autores devem submeter um manuscrito que apresente claramente as duas versões. A diferença de opinião deve ser explicada em uma carta de submissão. O processo normal de revisão pelos pares e pelo editor pode ajudar os autores a resolver suas discordâncias com relação à análise ou à interpretação.

Se a polêmica não pode ser resolvida e o estudo merece uma publicação, ambas as versões devem ser publicadas. As opções são publicar dois artigos sobre o mesmo estudo ou um único artigo com duas análises ou interpretações. Nesses casos, seria apropriado para os editores publicar uma declaração descrevendo o desacordo e a participação da revista nas tentativas de resolvê-lo.

\section{Resultados}

III.D.4. b. Diferenças nos Relatos dos Métodos e dos

Se a controvérsia se refere a opiniões divergentes sobre o que foi realmente feito ou observado durante o estudo, o editor da revista deve recusar a publicação até que a discordância seja resolvida. Não se deve esperar que a revisão pelos pares resolva esses problemas. Se houver alegações de desonestidade ou fraude, os editores devem informar às autoridades competentes; os autores devem ser notificados da intenção do editor de reportar uma suspeita de má conduta durante a pesquisa.

III.D.5. Manuscritos Concorrentes Baseados no Mesmo Banco de Dados

Os editores, por vezes, recebem manuscritos, proveniente de grupos de pesquisa diferentes que analisaram os 
mesmos dados (por exemplo, de um banco de dados público). Os manuscritos podem diferir nos seus métodos analíticos, nas conclusões ou em ambos. Cada manuscrito deve ser considerado separadamente. Se a interpretações dos dados é muito semelhante, é razoável, mas não obrigatório, que os editores dêem preferência ao manuscrito recebido em primeiro lugar. Contudo, a avaliação editorial das submissões múltiplas pode estar justificada nessas circunstâncias e pode até mesmo haver uma boa razão para a publicação de mais de um manuscrito, pois as diferenças das abordagens analíticas podem ser complementares e igualmente válidas.

\section{III.E. Correspondência}

O autor/avalista responsável pela correspondência tem a responsabilidade de comunicar-se com a revista, mas o CIERM recomenda que os editores enviem uma cópia de qualquer correspondência para todos os autores listados.

As revistas biomédicas devem colocar à disposição dos seus leitores um mecanismo para submissão de comentários, perguntas ou críticas sobre os artigos publicados, assim como relatos e comentários breves não relacionados a artigos publicados anteriormente. Provavelmente, mas não necessariamente, essas comunicações adquiram a forma de uma seção ou coluna de correspondência. Os autores dos artigos discutidos na seção de correspondência devem ter uma oportunidade de resposta, de preferência no mesmo fascículo no qual a correspondência original aparece. Os autores da correspondência devem fazer uma declaração de conflitos de interesse.

A correspondência publicada pode ser editada por razões de extensão, correção gramatical ou do estilo da revista. Por outro lado, os editores podem decidir publicar a correspondência, sem nenhuma modificação, por exemplo, nas seções de respostas rápidas na Internet. A revista deve mencionar sua política editorial a esse respeito. Os autores têm que aprovar as alterações editoriais que alteram o conteúdo ou o tom de uma carta ou de uma resposta. Em todos os casos, os editores devem esforçar-se para não publicar declarações descorteses, indevidas ou difamatórias e não devem permitir argumentação ad hominem com a intenção de desmerecer opiniões ou achados.

Embora os editores tenham a prerrogativa de rejeitar a correspondência que seja irrelevante, sem interesse ou que não seja convincente, têm a responsabilidade de permitir a expressão de várias opiniões. A coluna da correspondência não deve ser usada meramente para promover os pontos de vista da revista ou dos editores.

Em nome da imparcialidade e a fim de manter a correspondência dentro de proporções administráveis, as revistas podem estabelecer limites de tempo para resposta ao material publicado e para o debate de um determinado assunto. As revistas devem também decidir se irão notificar os autores quando uma correspondência relacionada aos seus artigos publicados vai aparecer na seção padrão ou na de respostas rápidas. As revistas também devem estabelecer normas com respeito ao arquivamento das correspondências não editadas que são publicadas por via eletrônica. Essas normas devem ser publicadas tanto na versão impressa como na versão eletrônica da revista.

\section{Especiais \\ III.F. Suplementos, Números Temáticos e Séries}

Os suplementos são coletâneas de artigos que abordam tópicos ou temas relacionados, sendo publicados como um fascículo separado da revista ou como parte de um fascículo regular e são, geralmente, patrocinados por outras fontes que não aquelas que financiam normalmente a publicação da revista. Os suplementos podem servir a algumas finalidades úteis: educação, intercâmbio das informações sobre a pesquisa, facilidade do acesso a um determinado conteúdo e melhoria da cooperação entre as entidades acadêmicas e empresariais. Como as fontes de financiamento podem influenciar o conteúdo dos suplementos pela escolha de assuntos e pontos de vista, as revistas devem adotar os princípios abaixo mencionados. Esses mesmos princípios se aplicam aos números temáticos e às séries especiais que recebem financiamento externo e/ou que têm editores convidados.

1. O editor da revista deve assumir total responsabilidade pelas políticas, práticas e conteúdo dos suplementos, incluindo o controle absoluto da decisão de publicar todas as partes do suplemento. A edição pela organização financiadora não deve ser permitida.

2. O editor da revista deve conservar a autoridade para enviar os manuscritos do suplemento para a revisão externa pelos pares e para rejeitar os manuscritos submetidos para o suplemento. Essas condições devem ser conhecidas dos autores e dos editores externos do suplemento antes que se inicie o processo editorial do suplemento.

3. O editor da revista deve aprovar a indicação de qualquer editor externo para o suplemento e ter a responsabilidade pelo trabalho desse editor externo.

4. As fontes de financiamento da pesquisa e da publicação, assim como o nome dos produtos que a fonte financiadora produz e que se relacionam com o suplemento, devem ser mencionados em local bem visível do suplemento, de preferência em cada página. Sempre que possível, o financiamento deve vir de mais de um patrocinador.

5. A propaganda nos suplementos deve seguir as mesmas regras daquelas do restante da revista.

6. Os editores da revista devem possibilitar aos leitores distinguir claramente entre as páginas editoriais normais e as páginas do suplemento.

7. Os editores da revista e os editores do suplemento não devem aceitar favores pessoais ou remuneração dos patrocinadores do suplemento.

8. A publicação secundária nos suplementos (republicação de artigos já publicados em outras revistas) deve estar identificada claramente pela citação do artigo original. Os suplementos devem evitar a publicação redundante ou duplicada. Os suplementos não devem publicar de novo os resultados das pesquisas, mas uma nova publicação, de diretrizes ou de outra matéria de interesse público, pode ser adequada.

9. Os princípios de autoria e a declaração de potencial conflito de interesse, mencionados em outra parte deste documento, devem ser aplicados aos suplementos. 


\section{III.G. Publicação Eletrônica}

A maior parte das revistas biomédicas é publicada atualmente tanto na versão impressa como na versão eletrônica e algumas são publicados somente sob a forma eletrônica. Em nome da clareza e da consistência, as recomendações deste documento devem ser aplicadas às informações médicas e de saúde publicadas eletronicamente, haja vista que a publicação eletrônica (aí incluída a Internet) deve ser igual à versão impressa.

A natureza da publicação eletrônica requer algumas considerações especiais, algumas fazendo parte e outras fora do escopo deste documento. Como normas mínimas, a página eletrônica deve indicar: os nomes, as credenciais apropriadas, as afiliações e os conflitos de interesse pertinentes dos editores, dos autores e dos colaboradores; a documentação e a atribuição das referências e fontes de todo o conteúdo; a informação sobre os direitos autorais; a declaração de propriedade do sítio e a declaração de patrocínio, dos anunciantes e do financiamento por empresas comerciais.

A existência de atalhos, de um sítio médico ou de saúde na Internet, para outro sítio, pode ser percebida como uma recomendação implícita da qualidade do segundo sítio. As revistas devem, então, ter cautela em criar atalhos com outros sítios; quando os usuários acessam um outro sítio, é útil avisá-los por meio de uma mensagem explícita que eles estão saindo da página eletrônica da revista. Se os atalhos para outros sítios forem colocados com intenções comerciais, isso deve ser claramente mencionado. Todas as datas de publicação e de atualizações do conteúdo devem estar indicadas. Tanto na apresentação sob forma eletrônica como na impressa, as mensagens publicitárias e promocionais não podem ser justapostas com o conteúdo editorial e o conteúdo comercial deve ser identificável como tal.

A publicação eletrônica é uma área que está em constante evolução. Os editores devem elaborar, disponibilizar para os autores e implementar políticas sobre questões específicas das publicações eletrônicas. Tais questões incluem arquivamento, correção de erros, controle da versão, escolha da forma impressa ou eletrônica da revista como a publicação de referência e publicação de material auxiliar.

Sob nenhuma hipótese, a revista deve remover um artigo da sua página eletrônica ou do seu arquivo. Se uma correção ou retratação se torna necessária, a explicação deve ser mencionada adequadamente e comunicada, tão logo quando possível, em uma página citada num fascículo subseqüente da revista.

A preservação dos artigos eletrônicos em um arquivo permanente é essencial para o registro histórico. $\mathrm{O}$ acesso ao arquivo deve ser imediato e deve ser controlado por terceiros, tal como uma biblioteca e não pelo dono da editora. $\mathrm{O}$ depósito em vários arquivos é incentivado.

\section{III.H.Propaganda}

A maioria das revistas médicas tem propaganda, que geram receita para aqueles que as publicam, mas a publicidade não pode influenciar as decisões editoriais. As revistas devem ter políticas escritas, formais e explícitas com relação à propaganda, tanto na versão impressa como na versão eletrô- nica; a política de publicidade na página eletrônica deve ser tão próxima quanto possível da política relacionada à versão impressa. Os editores devem ter autoridade total e definitiva para aprovar os anúncios e para fazer valer a política da propaganda.

Quando possível, os editores devem utilizar os julgamentos de órgãos independentes para revisar a publicidade. Os leitores devem ser capazes de distinguir claramente entre material de propaganda e matéria editorial. A justaposição do material editorial e do material de propaganda em relação aos mesmos produtos ou assuntos, deve ser evitada. A intercalação das páginas de publicidade dentro dos artigos interrompe o fluxo do conteúdo editorial e deve ser desestimulada. A propaganda não deve ser vendida com a condição de aparecer no mesmo fascículo de um determinado artigo.

As revistas não devem ser dominadas pela propaganda, mas os editores devem ter cuidado com a publicação de anúncios de apenas um ou dois anunciantes, pois os leitores podem imaginar que esses anunciantes influenciaram o editor.

As revistas não devem publicar anúncios de produtos sabidamente danosos à saúde - por exemplo, do fumo. Os editores devem assegurar que seja cumprida a legislação regulatória em vigor para anúncios, específica dos seus países ou senão, criarem suas próprias normas. Os interesse das organizações ou agências não devem controlar os anúncios classificados ou de outro formato, exceto onde exigido por lei. Finalmente, os editores devem levar em conta, para publicação, todas as críticas aos anúncios.

\section{I. Revistas Médicas e os Meios de Comunicação}

O interesse do público leigo, nas notícias sobre pesquisa médica, levaram os meios de comunicação a competir intensamente em busca das informações sobre as pesquisas. Os pesquisadores e as instituições, algumas vezes, estimulam os relatos da pesquisa nos meios de comunicação, antes da publicação na íntegra em uma revista científica, por intermédio de entrevistas ou de conferências de imprensa.

O público tem direito às informações médicas importantes dentro de um prazo razoável e os editores têm a responsabilidade de facilitar o processo. As revistas biomédicas são publicados, em primeiro lugar, para os seus leitores, mas o público leigo tem um interesse legítimo nos seus conteúdos: um equilíbrio adequado entre esses interesses deve orientar a interação das revistas com os meios de comunicação. Na sua prática, os médicos precisam das comunicações científicas disponíveis com todos os detalhes, antes que possam aconselhar os seus pacientes sobre as conclusões dos relatos. Além disso, os relatos da mídia sobre a pesquisa científica antes que o trabalho tenha sido submetido à revisão pelos pares e aprovado totalmente, podem contribuir para a divulgação de conclusões imprecisas ou prematuras.

Em alguns países, foi estabelecido um sistema de proibição para evitar a publicação de matéria na mídia leiga antes que a pesquisa original, na qual a matéria está baseada, seja publicada na revista científica. Essa proibição cria um "campo regulatório" que agrada à maioria dos jornalistas, pois diminui a pressão sobre eles para publicar matérias sem o tem- 
po necessário para prepará-las cuidadosamente. Uma coerência sobre a melhor hora para publicar as informações biomédicas é também importante para minimizar o impacto econômico, pois alguns artigos contêm informações que têm grande potencial de influenciar os mercados financeiros. Por outro lado, o sistema de embargo tem sido acusado de estar beneficiando os interesses das revistas e impedindo a rápida disseminação das informações científicas.

Quando buscam estabelecer uma política editorial sobre essas questões, os editores podem considerar úteis as seguintes recomendações:

- Os editores podem promover a transmissão ordenada, para o público leigo, das informações médicas geradas pelos pesquisadores, por meio das revistas com revisão pelos pares. Isso pode ser realizado, por meio de um acordo com os autores de que eles não divulgarão seu trabalho, enquanto o manuscrito estiver sendo avaliado ou estiver no prelo e com um acordo com a mídia de que as matérias não serão divulgadas antes da publicação da pesquisa original na revista científica; em troca, a revista cooperará com os meios de comunicação na preparação de matérias precisas.

- Os editores devem ter em mente que o sistema de embargo funciona com base no sistema de ética; não existe nenhuma imposição formal ou mecanismo de policiamento. Se houver a decisão de uma parte significativa dos veículos de comunicação ou das revistas biomédicas de não respeitar a proibição, o sistema de embargo caminhará para uma rápida dissolução.

- Muito pouca pesquisa médica tem implicações clínicas importantes tão claras e urgentes para a saúde pública que justifique que seja divulgada antes da publicação na íntegra em uma revista científica. Em circunstâncias excepcionais, contudo, as autoridades competentes responsáveis pela saúde pública devem decidir e responsabilizar-se pela divulgação antecipada das informações para os médicos e para os meios de comunicação. Se o autor e as autoridades competentes quiserem que um manuscrito seja submetido a uma determinada revista, o editor deve ser consultado antes de qualquer divulgação pública. Se os editores concordam com a necessidade da divulgação imediata, eles devem abrir mão das políticas editoriais que limitam a divulgação antes da publicação.

- As políticas destinadas a restringir a divulgação antes da publicação não devem ser aplicadas a relatos na mídia sobre apresentações nos congressos científicos nem aos resumos apresentados nesses congressos (ver Publicação Redundante). Os pesquisadores que apresentam os seus trabalhos em um congresso científico devem sentir-se à vontade para discutir suas apresentações com os jornalistas, mas devem evitar fornecer mais pormenores sobre seus estudos do que aquilo que foi apresentado nas palestras.

- Quando um artigo está prestes a ser publicado, os editores devem auxiliar os meios de comunicação a preparar matérias precisas, fornecendo informações, respondendo perguntas, fornecendo exemplares antecipados da revista ou encaminhando os jornalistas aos especialistas adequados. Essa ajuda deve estar condicionada à cooperação da mídia em fazer coincidir a publicação da sua matéria com a publicação do artigo científico.
- Os editores, os autores e os meios de comunicação devem aplicar os princípios descritos acima a qualquer material divulgado antecipadamente nas versões eletrônicas das revistas.

\section{III.J. Obrigação de Registrar os Ensaios Clínicos}

O CIERM acredita que seja importante apoiar um banco de dados dos ensaios clínicos que seja abrangente e disponível para o público. O CIERM define um ensaio clínico como qualquer projeto de pesquisa que aloca prospectivamente os sujeitos de pesquisa para intervenção ou para comparação concorrente ou grupos de controle, a fim de estudar as relações de causa e efeito entre uma intervenção médica e um desfecho clínico. As intervenções médicas incluem fármacos, procedimentos cirúrgicos, equipamentos, tratamentos comportamentais, modificações no processo de cuidados, etc.

Os editores membros do CIERM exigirão, como condição para a submissão as suas revistas, que haja cadastramento em um registro público de ensaios. Os detalhes dessa política estão contidos em uma série de editoriais (ver Editoriais http://www.icmje.org/clin_trialup.htm, na seção Perguntas Mais Freqüentes http://www.icmje.org/faq.pdf). O CIERM incentiva que os editores de outras revistas biomédicas adotem uma política semelhante.

O CIERM não endossa nenhum registro em particular, mas as suas revistas devem solicitar dos autores o registro dos seus ensaios em um registro que satisfaça alguns critérios. O registro deve ser de acesso público e gratuito. $\mathrm{O}$ registro deve ser aberto a todos os cadastros prospectivos e deve ser administrado por uma organização sem fins lucrativos. Deve haver um mecanismo para assegurar a validade dos dados do registro e ele deve ser passível de busca eletrônica. Um registro aceitável deve incluir, no mínimo, os dados mencionados na Tabela 1 www.icmje.org/clin_trialup.htm\#table1. O registro do ensaio clínico, com campos em branco ou com informações que contenham terminologia pouco informativa, não é adequado.

É importante frisar que o CIERM requer o registro da metodologia do ensaio, mas não o registro dos resultados; o comitê reconhece os potenciais problemas que poderiam advir da divulgação dos resultados da pesquisa, os quais não tenham sido submetidos a um processo independente de revisão pelos pares. Contudo, o CIERM compreende que o Decreto da U.S. Food and Drug Administration (FDA) de 2007 preconiza que os pesquisadores registrem os resultados. O CIERM não considerará os resultados divulgados no mesmo registro primário do ensaio clínico, se os resultados forem divulgados sob a forma tabular preconizada pelo FDA. Os pesquisadores precisam estar cientes que os editores das revistas que seguem as recomendações do CIERM podem considerar como publicação prévia a descrição mais detalhada dos resultados dos ensaios e os resultados publicados em outros registros primários (no caso da FDA, o ClinicalTrials.gov). O CIERM imagina que as condições para o registro dos resultados sofrerão grandes mudanças nos próximos anos e que o CIERM tenha que alterar essas recomendações à medida que outras agências instituam outras instruções para o registro dos resultados. 
O CIERM recomenda que as revistas publiquem o número de registro do ensaio no fim do resumo. $\mathrm{O}$ comitê recomenda também que, quando um número de registro está disponível, os autores coloquem o número de registro na primeira vez que usarem um acrônimo de ensaio ao se referirem ao ensaio que estão relatando ou a outros ensaios que são mencionados no manuscrito.

\section{PREPARAÇÃO E SUBMISSÃO DO MANUSCRITO}

\section{IV.A. Preparação do Manuscrito para Submissão a uma Revista Biomédica}

Os editores e os revisores passam muitas horas lendo os manuscritos e, por isso, gostam de receber artigos fáceis de ler e de editar. Muitas das informações inseridas nas Instruções aos Autores de uma revista se destinam a realizar aquele objetivo de uma maneira que satisfaça às necessidades editoriais específicas de cada revista. As informações que se seguem fornecem uma orientação na preparação dos manuscritos para qualquer revista.

\section{IV.A.1.a. Princípios Gerais}

$\mathrm{O}$ texto dos artigos das pesquisas observacionais e experimentais é geralmente (mas não necessariamente) dividido nas seguintes seções: Introdução, Métodos, Resultados e Discussão. Essa estrutura, denominada "IMRAD", não é simplesmente um formato arbitrário de publicação, mas, ao contrário, uma reflexão direta do processo da descoberta científica. Os artigos longos podem necessitar de subtítulos dentro de algumas seções (principalmente nas de Resultados e de Discussão) para tornar o conteúdo mais claro. Outros tipos de artigos, tais como relatos de casos, revisões e editoriais necessitam provavelmente de formatos diferentes.

Os formatos eletrônicos criaram as oportunidades para acrescentar detalhes ou seções inteiras, somente na versão eletrônica, colocando mais informações em atalhos, entrecruzando-se ou extraindo trechos dos artigos, etc. Os autores precisam trabalhar em conjunto com os editores no desenvolvimento e na utilização desses novos formatos de publicação e devem submeter, para a revisão pelos pares, matérias eletrônicas suplementares.

O espaçamento duplo ao longo de todo o manuscrito - inclusive na página de rosto, no resumo, no texto, nos agradecimentos, nas referências, nas tabelas e nas legendas - e margens amplas permitem aos editores e revisores editar o texto linha por linha e acrescentar comentários e perguntas, diretamente na cópia em papel. Se os manuscritos são submetidos sob forma eletrônica, os arquivos devem ter espaço duplo, para facilitar a impressão para o processo de revisão e de edição.

Os autores devem numerar consecutivamente todas as páginas do artigo, começando com a página de rosto, a fim de facilitar o processo editorial.

IV.A.1.b. Diretrizes para Relatos de Desenhos de Estudo Específicos

Os relatórios das pesquisas omitem freqüentemente informações importantes. Diretrizes para relatos (Tabela 2) fo- ram desenvolvidas para alguns desenhos de estudo e algumas revistas podem solicitar aos autores que elas sejam seguidas. Os autores devem consultar as Instruções aos Autores da revista que escolheram.

As normas gerais listadas na seção seguinte se relacionam aos elementos essenciais dos relatos de todos os desenhos de estudo. Os autores são estimulados a consultar as diretrizes de relatos pertinentes aos seus desenhos de pesquisa específicos. Para os relatos de ensaios randomizados e controlados, os autores devem consultar as normas CONSORT www.consort-statement.org. Essa diretriz fornece um conjunto de recomendações que abrangem uma lista de itens a relatar e um diagrama de fluxo dos pacientes.

\section{IV.A.2. A Página de Rosto}

A página de rosto deve trazer as seguintes informações:

1. O título do artigo. Os títulos concisos são mais fáceis de ler do que aqueles longos e complicados. No entanto, os títulos muito curtos podem não mostrar informações importantes, tais como o desenho do estudo (particularmente importante para identificar ensaios randomizados e controlados). Os autores devem incluir, no título, todas as informações que aumentam a sensibilidade e a especificidade da recuperação eletrônica do artigo.

2. Os nomes dos autores e suas filiações institucionais. Algumas revistas publicam a(s) maior(es) titulação(ções) acadêmica(s) de cada autor, enquanto outras não o fazem.

3. O nome do (s) departamento(s) e instituição(ções) aos quais o trabalho deve ser atribuído.

4. Renúncia a um direito legal, se houver.

5. Informações para contato com os autores responsáveis pela correspondência.. O nome, o endereço de correio, os números de telefone e fax e o endereço eletrônico do autor responsável pela correspondência sobre o manuscrito (o "autor correspondente"; esse autor pode ou não ser o "avalista" da integridade do estudo). $\mathrm{O}$ autor responsável pela correspondência deve indicar claramente se o seu endereço eletrônico pode ser publicado.

6. O nome e o endereço do autor a quem os pedidos de cópias do artigo devem ser dirigidos ou uma declaração de que os autores não disponibilizarão cópias

7. Fonte(s) de auxílio sob a forma de subvenções, equipamentos e fármacos

8. Um título resumido. Algumas revistas solicitam um título resumido, geralmente com não mais que 40 caracteres (incluindo letras e espaços), colocado como rodapé da página de rosto. Os títulos resumidos são impressos na maioria das revistas, mas são algumas vezes também empregados na secretaria editorial para arquivar e localizar os manuscritos.

9. Contadores de palavras. Um contador de palavras só para o texto (excluindo o resumo, os agradecimentos, as legendas das figuras e as referências) permite aos editores e aos revisores avaliarem se as informações contidas no artigo justificam o espaço destinado para elas e se o manuscrito submetido está dentro dos limites de palavras estabelecidos 
pela revista. Pela mesma razão, é também útil um contador de palavras independente para o Resumo

10. O número de figuras e tabelas. É difícil para o corpo editorial e para os revisores saberem se as figuras e as tabelas, que deveriam acompanhar um manuscrito, foram realmente incluídas, a menos que os números das figuras e das tabelas sejam anotadas na página de rosto.

\section{IV.A.3. Página da Declaração de Conflito de Interesse}

Para evitar que as informações sobre potencial conflito de interesse dos autores passem despercebidas ou mal apresentadas, elas precisam fazer parte do manuscrito. Contudo, essas informações devem também ser incluídas em uma ou mais páginas separadas, imediatamente após a página de rosto. Cada revista pode diferir sobre onde incluir essas informações e algumas revistas não encaminham as informações sobre conflitos de interesse para os revisores (ver Seção II.D. Conflitos de interesse)

\section{IV.A.4. Resumo}

O resumo (variam as normas para o tamanho e o formato) deve vir após a página de rosto. No resumo deve constar o contexto ou a introdução do estudo, o objetivo do estudo, os procedimentos básicos (critérios de seleção dos sujeitos de pesquisa ou dos animais de laboratório, os métodos observacionais e os métodos analíticos), os resultados principais (mencionando os tamanhos do efeito e, se possível, sua significância estatística) e as conclusões principais. $\mathrm{O}$ resumo deve enfatizar os novos e importantes aspectos do estudo ou das observações. Os artigos sobre ensaios clínicos devem conter resumos que incluam os itens que o grupo CONSORT identificou como essenciais www.consortstatement.org.

Como os resumos são a única parte importante do artigo indexada em muitas bases de dados eletrônicas, e a única parte que muitos leitores lêem, os autores precisam ter cuidado para que os resumos reflitam adequadamente o conteúdo do artigo. Infelizmente, as informações contidas em muitos resumos diferem daquelas encontradas no texto (6). $\mathrm{O}$ formato exigido para os resumos estruturados difere de revista para revista e algumas revistas utilizam mais de um formato; os autores devem preparar seus resumos no formato especificado pela revista que escolheram.

O CIERM recomenda que as revistas publiquem o número de registro do ensaio no fim do resumo. O CIERM recomenda ainda que, quando haja um número de registro, os autores ponham esse número na primeira vez que eles utilizarem um acrônimo para se referir ao ensaio que estão reportando ou a outros ensaios que eles mencionam no manuscrito.

\section{IV.A.5. Introdução}

A introdução fornece o contexto ou o cenário do estudo (isto é, a natureza do problema e sua importância). Menciona o objetivo da pesquisa ou a hipótese testada do estudo ou da observação; o objetivo da pesquisa é frequëntemente melhor apresentado, quando elaborado como uma pergunta. Tantos os objetivos principais como os objetivos secundários devem ser claros e qualquer análise prevista de subgrupo deve ser descrita. Fornecer somente as referências estritamente pertinentes e não incluir dados ou conclusões do trabalho que está sendo relatado.

\section{IV.A.6. Métodos}

A seção de Métodos só deve incluir as informações que estavam disponíveis no momento da elaboração do projeto ou protocolo do estudo; todas as informações obtidas durante a realização do estudo pertencem à seção de Resultados.

\section{IV.A.6.a. Seleção e Descrição dos Sujeitos de Pesquisa}

Descrever a seleção dos participantes nos estudos observacionais ou experimentais (sujeitos de pesquisa ou animais de laboratório, incluindo os controles) de modo claro, mencionando os critérios de inclusão e de exclusão, assim como uma descrição da população alvo. Como a importância das variáveis como idade e sexo para o objetivo da pesquisa nem sempre está clara, os autores devem explicá-las quando elas são incluídas no relato do estudo - por exemplo, os autores devem explicar porque apenas pacientes de certas idades foram incluídos ou porque as mulheres foram excluídas. $\mathrm{O}$ princípio que orienta deve ser o da clareza de como e porque um estudo foi realizado de determinada maneira. Quando os autores utilizam variáveis como raça ou etnicidade, devem definir como as variáveis foram medidas e justificar a sua importância.

IV.A.6.b. Informações técnicas. Identificar os métodos, os equipamentos (mencionar o nome e o endereço do fabricante entre parênteses) e os procedimentos em detalhes suficientes para permitir que outros reproduzam os resultados. Dar as referências dos métodos já estabelecidos, inclusive dos métodos estatísticos (ver abaixo); fornecer as referências e as descrições sucintas dos métodos já publicados, mas que não são muito bem conhecidos; descrever os métodos novos ou que sofreram modificações importantes, explicando as razões para utilizá-los e avaliando suas limitações. Identificar com precisão todos os fármacos e compostos químicos empregados, inclusive o(s) nome(s) genérico(s), dose(s) e via(s) de administração.

Os autores ao submeterem manuscritos de revisão devem incluir uma seção com a descrição dos métodos utilizados para localizar, selecionar, extrair e sintetizar os dados. Esses métodos devem também fazer parte do Resumo.

IV.A.6.c. Estatística. Descrever os métodos estatísticos com detalhes para permitir que um leitor com conhecimento do assunto possa ter acesso aos dados originais para verificar os resultados apresentados. Quando possível, quantificar os achados e apresentá-los com adequados indicadores de erro de mensuração ou de incerteza (tais como os intervalos de confiança). Evitar confiar apenas nos testes de hipótese, tais como os valores de $P$, os quais não fornecem informações importantes sobre o tamanho do efeito. As referências sobre o desenho do estudo e sobre os métodos estatísticos devem ser, sempre que possível, de artigos clássicos (com indicação das páginas). Definir os termos estatísticos, as abreviações e a maioria dos símbolos. Especificar qual foi o software utilizado no computador. 


\section{IV.A.7. Resultados}

Apresentar os seus resultados em uma seqüência lógica no texto, nas tabelas e nas ilustrações, mencionando primeiro os achados mais importantes. Não repetir, no texto, todos os dados mostrados nas tabelas ou nas ilustrações; enfatizar ou resumir somente as observações importantes. Matérias suplementares ou adicionais e detalhes técnicos podem ser colocados em um apêndice, onde ficarão acessíveis, sem interromper o fluxo do texto ou podem ser publicados somente na versão eletrônica da revista.

Quando os dados são resumidos na seção de Resultados, apresentar os resultados numéricos não apenas como valores derivados (por exemplo, percentagens), mas também em números absolutos a partir dos quais os valores derivados foram calculados e especificar os métodos estatísticos usados para analisá-los. Restringir as tabelas e figuras àquelas necessárias para explicar o argumento do artigo e para avaliar os dados que suportam esse argumento. Utilizar os gráficos como uma alternativa às tabelas com muitas entradas; não duplicar os dados nos gráficos e nas tabelas. Evitar acepções não técnicas de termos técnicos em estatística, tais como "aleatório" (que implica num método de randomização), "normal", "significante", "correlações" e "amostra".

Quando cientificamente adequado, as análises dos dados por meio de variáveis como idade e sexo devem ser incluídas.

\section{IV.A.8. Discussão}

Enfatizar os aspectos novos e importantes do estudo e as conclusões que advêm deles. Não repetir, em detalhes, os dados ou outras informações inseridos nas seções de Introdução ou de Resultados. Para os estudos experimentais, é útil começar a discussão por um breve resumo dos principais achados, depois, explorar os mecanismos ou explicações possíveis para esses resultados, comparar e cotejar os resultados com outros estudos semelhantes, mencionar as limitações do estudo e explorar as implicações dos resultados para pesquisas futuras e para a prática clínica.

Relacionar as conclusões com os objetivos do estudo, mas evitar afirmações e conclusões incondicionais não adequadamente corroboradas pelos dados. Especialmente, evitar fazer afirmações sobre benefícios econômicos e custos, a não ser que seus manuscritos contenham dados e análises econômicas apropriados. Evitar reivindicar prioridade e alusão a trabalho ainda não terminado. Estabelecer novas hipóteses quando for o caso, mas deixar claro que são hipóteses.

\section{IV.A.9. Referências}

\section{ferências}

IV.A.9.a. Considerações Gerais Relacionadas às Re-

Embora as referências a artigos de revisão possam ser uma maneira eficaz de orientar os leitores em grande parte da literatura, os artigos de revisão nem sempre refletem o trabalho original com precisão. Os leitores devem, então, ter acesso direto às referências das pesquisas originais, sempre que possível. Por outro lado, extensas listas de referências sobre os artigos originais de um determinado tópico podem utilizar espaço excessivo da página impressa. Um pequeno número de referências dos artigos originais principais servirá frequientemente tão bem quanto listas mais completas, principalmente porque, atualmente, as referências podem ser inseridas na versão eletrônica dos artigos publicados, já que a busca da literatura eletrônica permite aos leitores recuperar eficientemente a literatura publicada.

Evitar o uso de resumos como referências. As referências a artigos aceitos, mas ainda não publicados devem ser designadas como "no prelo" ou "em impressão"; os autores devem obter uma autorização por escrito para citar esses artigos, bem como verificar se eles foram aceitos para publicação. As informações originadas de manuscritos submetidos, mas ainda não aceitos devem ser citadas no texto como "observações não publicadas" com a permissão por escrito do autor.

Evitar citar uma "comunicação pessoal", a não ser que ela forneça informações essenciais ainda não disponíveis em nenhuma fonte pública; nesse caso, o nome da pessoa e a data da comunicação devem ser citados entre parênteses no texto. Para artigos científicos, obter do autor da comunicação pessoal, por escrito, a permissão e a confirmação de que a informação foi citada de forma precisa.

Algumas revistas verificam a precisão de todas as citações nas referências, mas nem todas o fazem; assim, os erros de citação, às vezes, aparecem na versão publicada dos artigos. Para minimizar esses erros, verificar as referências confrontando-as com os documentos originais. Os autores são os responsáveis em verificar que nenhuma das referências cite artigos retratados, exceto no contexto da menção à própria retratação. Para os artigos publicados em revistas indexadas no MEDLINE, o CIERM considera o PubMed www.ncbi.nlm.nih.gov/sites/entrez/ a fonte com autoridade para dar informações sobre retratações. Os autores podem identificar artigos retratados no MEDLINE por meio do termo de busca seguinte, em que pt entre colchetes significa tipo de publicação: Retracted publication [pt] no PubMed.

\section{IV.A.9.b.Estilo e formatos das referências}

O estilo para referências adotado por estas Normas se baseia principalmente no estilo do American National Standards Institute (ANSI), adaptado pela NLM para seus bancos de dados. Os autores devem consultar o Citing Medicine da NLM www.ncbi.nlm.nih.gov/books/ bv.fcgi?rid=citmed.TOC\&amp; depth=2 para as informações sobre os formatos recomendados para uma variedade de tipos de referências.

As referências devem ser numeradas consecutivamente na ordem em que são mencionadas no texto pela primeira vez. Identificar as referências no texto, nas tabelas e nas legendas com algarismos arábicos entre parênteses. As referências citadas somente nas tabelas ou nas legendas das figuras devem ser numeradas de acordo com a seqüência estabelecida pela primeira menção no texto daquela determinada tabela ou figura. Os títulos das revistas devem ser abreviados de acordo com o estilo utilizado no Index Medicus. Deve ser consultada a Lista de Revistas Indexadas pelo MEDLINE, colocada pela NLM na sua página eletrônica www.nlm.nih.gov/tsd/serials/lji.html. As revistas variam no 
modo como solicitam aos autores que citem as referências eletrônicas: entre parênteses no texto ou em referências numeradas após o texto. Os autores devem consultar a revista para a qual planejam submeter seu trabalho.

\section{IV.A.10. Tabelas}

As tabelas captam as informações de modo conciso e exibem-nas de maneira eficiente; elas também fornecem informações em qualquer nível desejado de detalhe ou precisão. A inclusão dos dados nas tabelas e não no texto, muitas vezes torna possível reduzir o tamanho do texto.

Digitar ou imprimir cada tabela em espaço duplo numa folha de papel separada. Numerar as tabelas consecutivamente na ordem de sua primeira citação no texto e inserir um título curto para cada uma. Não utilizar linhas internas horizontais ou verticais. Dar para cada coluna um título curto ou abreviado. Os autores devem colocar os textos explicativos como rodapé e não no título. Explicar, como notas de rodapé, todas as abreviações não padronizadas, utilizando os seguintes símbolos, em seqüência:

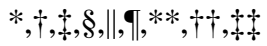

Identificar as medidas estatísticas das variações, tais como desvio padrão ou erro padrão da média.

Certificar-se de que cada tabela está citada no tex-

to.

Se forem utilizados dados publicados ou não publicados de outra fonte, obter uma autorização e agradecer a essa fonte adequadamente.

As tabelas adicionais com dados copiados muito extensos para serem publicadas na versão impressa, podem ser apropriados para a publicação na versão eletrônica da revista ou depositados em um arquivo ou disponibilizados aos leitores diretamente pelos autores. Uma declaração apropriada deve ser colocada no texto para informar aos leitores que essas informações adicionais estão disponíveis e onde foram colocadas. Submeter essas tabelas para consideração juntamente com o artigo, de forma que elas estejam disponíveis para os revisores.

\section{IV.A.11. Ilustrações (Figuras)}

As figuras devem ser desenhadas por profissionais e fotografadas ou submetidas como impressões digitalizadas com qualidade de fotografias. Além de solicitar uma versão das figuras adequada para impressão, algumas revistas pedem atualmente aos autores os arquivos eletrônicos das figuras em um formato (por exemplo: JPEG ou GIF) que produzirá imagens de alta qualidade na versão eletrônica da revista; os autores devem rever as imagens desses arquivos em uma tela de computador antes de submetê-las, para certificarem-se de que atendem aos seus próprios padrões de qualidade.

Para as radiografias, as tomografias computadorizadas e as outras imagens diagnósticas, assim como as fotos de espécimes patológicos ou fotomicrografias, enviar fotografias nítidas, impressas em papel brilhante, em preto e branco ou em outras cores, geralmente de 127 x $173 \mathrm{~mm}$ ( $5 \times 7$ polegadas $)$. Embora algumas revistas refaçam a arte das figuras, muitas não o fazem. As letras, os números e os símbolos das figuras, por isso, devem ser nítidos e uniformes e de tamanho suficiente para que permaneçam legíveis, quando reduzidos para publicação. As figuras devem ser tanto quanto possível autoexplicativas, pois muitas serão utilizadas diretamente nas apresentações como diapositivos. Os títulos e as explicações detalhadas devem ficar nas legendas e não nas próprias ilustrações.

As fotomicrografias devem ter marcadores internos de escala. Os símbolos, as setas ou as letras utilizadas nas fotomicrografias devem fazer contraste com o fundo.

As fotografias de pessoas potencialmente identificáveis devem vir acompanhadas de autorização por escrito para uso da fotografia.

As figuras devem ser numeradas consecutivamente de acordo com a ordem que foram citadas no texto. Se uma figura já houver sido publicada, deve-se dar crédito à fonte original e apresentar uma autorização por escrito do detentor dos direitos autorais da reprodução da figura. Exige-se a autorização independentemente da autoria ou do editor, exceto nos casos dos documentos de domínio público.

Para as ilustrações coloridas, verificar se a revista exige os negativos coloridos, as transparências positivas ou as impressões em cores. Os desenhos feitos para indicar a região a ser reproduzida podem ser úteis para o editor. Algumas revistas só publicam ilustrações coloridas se o custo adicional for pago pelo autor.

Os autores devem consultar a revista com respeito às normas para as figuras submetidas em formato eletrônico.

\section{IV.A.12. Legendas das Ilustrações (Figuras)}

Digitar ou imprimir as legendas das ilustrações com espaço duplo, começando em uma página separada, com números arábicos correspondentes às ilustrações. Quando se empregar símbolos, setas, números ou letras para identificar partes das ilustrações, identificar e explicar cada um com clareza na legenda. Explicar a escala interna e identificar o método da coloração nas fotomicrografias.

\section{IV.A.13. Unidades de Medida}

As medidas de comprimento, altura, peso e volume devem ser apresentadas no sistema métrico (metro, quilograma ou litro) com seus múltiplos decimais.

As temperaturas devem estar em graus Celsius. As pressões arteriais devem ser expressas em milímetros de mercúrio, a não ser que outras unidades sejam solicitadas especificamente pela revista.

As revistas variam quanto às unidades que utilizam para relatar os valores hematológicos, de química clínica ou de outras medidas. Os autores devem consultar as Instruções aos Autores de cada revista e reportar as informações laboratoriais tanto no sistema local quanto no International System of Units (SI). Os editores podem solicitar aos autores que acrescentem unidades alternativas ou não-SI, já que as unidades SI não são universalmente aceitas. As concentrações dos fármacos podem estar em unidades SI ou unidades de massa, mas a alternativa deve ser colocada entre parênteses, quando for apropriado. 


\section{IV.A.14. Abreviações e Símbolos}

Utilizar somente abreviações padronizadas; o emprego das abreviações não padronizadas pode confundir os leitores. Evitar abreviações no título. O termo por extenso, seguido pela abreviação entre parênteses deve ser empregado quando mencionado pela primeira vez, a não ser que a abreviação seja uma unidade de medida padrão.

\section{IV.B Envio do Manuscrito para a Revista}

Atualmente, um número crescente de revistas aceita a submissão eletrônica dos manuscritos, seja em disquete ou como um anexo do correio eletrônico ou, ainda, baixando diretamente o arquivo na página eletrônica da revista. A submissão eletrônica economiza tempo e dinheiro e permite que o manuscrito seja manipulado na forma eletrônica durante todo o processo editorial (por exemplo, quando ele é enviado para revisão). Os autores devem consultar as Instruções aos Autores da revista para instruções específicas sobre a submissão eletrônica.

Se uma versão em papel do manuscrito é submetida, enviar o número solicitado de cópias do manuscrito e das figuras; elas são todas necessárias para a revisão pelos pares e para a edição, pois não é tarefa da secretaria editorial fazer essas cópias.

Os originais devem ser acompanhados por uma carta de submissão, a qual deve conter as seguintes informações:

- uma declaração completa para o editor sobre todas as submissões e relatos anteriores que possam ser vistos como publicação redundante do mesmo trabalho ou de um muito semelhante. Qualquer trabalho nessa situação deve ser mencionado especificamente e referenciado no novo artigo. As cópias desse material devem ser incluídas com o artigo submetido, para auxiliar o editor a tratar dessa situação.

- uma declaração sobre as relações financeiras ou de outras naturezas que possam levar a um conflito de interesse, quando essas informações não estão inseridas no próprio artigo ou num formulário preenchido pelos autores

- uma declaração de que o manuscrito foi lido e aprovado por todos os autores; de que todas as normas de autoria descritas acima neste documento foram observadas e de que cada autor acredita que o manuscrito represente um trabalho honesto, se essas informações não foram fornecidas de outra forma (ver abaixo)

- o nome, o endereço e o número do telefone do autor responsável pela correspondência, o qual é responsável pela comunicação com os outros autores sobre as revisões e a aprovação final das provas, se essas informações não estão incluídas no próprio manuscritos.

A carta deve fornecer qualquer informação adicional que possa ser útil para o editor, como, por exemplo, o tipo ou formato do artigo em que o manuscrito se enquadra naquela determinada revista. Se o manuscrito foi submetido anteriormente a outra revista, é útil incluir, junto com o manuscrito submetido, os comentários daqueles revisores e do editor, assim como as respostas dos autores a esses comentários. Os editores estimulam os autores a submeterem essas comunicações anteriores, pois isso agiliza o processo de revisão.
Atualmente, muitas revistas fornecem uma lista de checagem pré-submissão que ajuda o autor a verificar que todos os componentes da submissão foram incluídos. Algumas revistas, hoje em dia, também solicitam que os autores completem as listas de checagem para relatos de certos tipos de estudo (por exemplo, a lista de checagem do CONSORT para os relatos de ensaios randomizados e controlados). Os autores devem procurar saber se a revista utiliza essas listas de checagem e enviá-las, se necessário, junto com o manuscrito.

Devem acompanhar o manuscrito, as cartas de permissão para reproduzir matéria ou utilizar ilustrações já publicadas anteriormente, para mencionar informações sobre pessoas identificáveis ou para agradecer pessoas por suas contribuições.

\section{REFERÊNCIAS}

\section{A. Referências Citadas Neste documento}

1. Davidoff F, for the CSE Task Force on Authorship. Who's the author? Problems with biomedical authorship, and some possible solutions. Science Editor. 2000;23:111-9.

2. Yank V, Rennie D. Disclosure of researcher contributions: a study of original research articles in The Lancet. Ann Intern Med. 1999;130:661-70.

3. Flanagin A, Fontanarosa PB, DeAngelis CD. Authorship for research groups. JAMA. 2002;288:3166-8.

4. Godlee F, Jefferson T. Peer Review in Health Sciences. London: BMJ Books; 1999.

5. World Medical Association Declaration of Helsinki: Ethical principles for medical research involving human subjects. JAMA. 2000;284:3043-5.

6. Pitkin RM, Branagan MA, Burmeister LF. Accuracy of data in abstracts of published research articles. JAMA. 1999;281:1110-1.E-mail: caguimaraes@gbl.com.br

\section{B. Outras Fontes de Informação Relacionadas a Re- vistas Biomédicas}

World Association of Medical Editors (WAME) www.wame.org/

Council of Science Editors www.councilscienceeditors.org/

European Association of Science Editors (EASE) www.ease.org.uk/

Cochrane Collaboration www.cochrane.org/

Committee on Publication Ethics (COPE) www.publicationethics.org.uk/

\section{SOBRE O COMITÊ INTERNACIONAL DE EDITORES DE REVISTAS MÉDICAS}

O CIERM é um grupo de editores de revistas de Medicina Interna cujos participantes se reúnem anualmente e financiam eles próprios o seu trabalho sobre as Normas para os Manuscritos. O CIERM gostaria de receber comentários sobre este documento e sugestões sobre os itens da pauta a ser discutida. 


\section{AUTORES DAS NORMAS PARA MANUSCRITOS SUBMETIDOS ÀS REVISTAS BIOMÉDICAS}

As revistas e organizações, cujos representantes integram o CIERM, e que aprovaram a revisão das Normas para Manuscritos, em setembro de 2008, são: Annals of Internal Medicine, British Medical Journal, Canadian Medical Association Journal, Croatian Medical Journal, Journal of the American Medical Association, Nederlands Tijdschrift voor Geneeskunde (The Dutch Medical Journal), New England Journal of Medicine, New Zealand Medical Journal, The Lancet, The Medical Journal of Australia, Tidsskrift for Den Norske Laegeforening (The Journal of the Norwegian Medical Association), Ugeskrift for Laeger (Journal of the Danish Medical Association), a U.S. NLM e a World Association of Medical Editors.

\section{USO, DISTRIBUIÇÃO E TRADUÇÃO DAS NORMAS}

Os usuários podem imprimir, copiar e distribuir gratuitamente este documento para finalidade educativa, sem fins lucrativos. O CIERM não tem estoque de cópias impressas deste documento.

A política do CIERM é que as organizações interessadas criem atalhos para o documento oficial em língua inglesa no endereço www.ICMJE.org. O CIERM não endossa a inserção deste documento em outros sítios da Internet que não o do CIERM.

O CIERM estimula as organizações a reimprimir ou traduzir este documento em outros idiomas que não o inglês, sem fins lucrativos. No entanto, o CIERM não tem recursos para traduzir, verter ou aprovar cópias reimpressas ou traduções deste documento. Assim, quaisquer traduções devem colocar, em local bem visível, a seguinte declaração: "Esta é uma [cópia/tradução em língua (nome da lingua)] das Normas para Manuscritos Submetidos às Revistas Biomédicas, elaboradas pelo CIERM. (inserir o nome da organização) preparou esta tradução com o apoio de (inserir o nome da fonte de financiamento, se houver). O CIERM nem endossou nem aprovou o conteúdo desta cópia/tradução. O CIERM atualiza periodicamente as Normas, de modo que esta cópia/tradução elaborada em (inserir data) pode não representar com precisão a versão oficial mais recente das Normas para Manuscritos Submetidos às Revistas Biomédicas, a qual se encontra no endereço www.ICMJE.org.

Não exigimos que as pessoas ou as organizações, que reimprimam ou traduzam as Normas para Manuscritos Submetidos às Revistas Biomédicas, obtenham uma permissão formal, por escrito, do CIERM. Entretanto, o CIERM solicita que essas pessoas ou organizações forneçam à secretaria do CIERM a citação dessa cópia ou tradução, de modo que o CIERM possa manter um arquivo dessas versões do documento.

\section{PERGUNTAS}

Antes de enviar uma pergunta, por favor, consultar as Perguntas Mais Freqüentes no endereço www.icmje.org/ faq.pdf, pois essa seção da página eletrônica fornece as respostas para a maioria das perguntas mais comuns.

As perguntas sobre as Normas devem ser enviadas a Christine Laine, MD, MPH, ICMJE Secretariat office, American College of Physicians, 190 N. Independence Mall West, Philadelphia, PA 19106-1572,USA.e-mail claine@acponline.org. Por favor, não façam perguntas à secretaria do CIERM sobre determinados estudos, estilos ou políticas das revistas. O CIERM não arquiva as informações para contato com determinada revista. Os manuscritos a serem submetidos a uma revista devem ser enviados à revista e não ao CIERM.

Esta é uma tradução em língua portuguesa das Normas para Manuscritos Submetidos às Revistas Biomédicas, elaboradas pelo CIERM. A Revista do Colégio Brasileiro de Cirurgiões preparou esta tradução. O CIERM nem endossou nem aprovou o conteúdo desta cópia. O CIERM atualiza periodicamente as Normas, de modo que esta tradução elaborada em outubro de 2008 pode não representar com precisão a versão oficial mais recente das Normas para Manuscritos Submetidos às Revistas Biomédicas, a qual se encontra no endereço 〈www.ICMJE.org〉 (Rev. Col. Bras. Cir. 2008; 35(6): 425-441).

Descritores: Ciência da Informação. Comunicação. Editoração. Disseminação de Informação. Linguagem. Tradução. Artigo de revista. Vancouver

Endereço para correspondência:

Carlos Alberto Guimaraes

R.Luis Murat,180 - Granja Comary

25959-060 - Teresópolis - RJ 